\title{
A AUTORIDADE DOCENTE E A COMPLEXA FABRICAÇÃO DO COMUM: TENSŌES E CRÍTICAS NA INTERVENÇÃO DAS FAMÍLIAS NO TRABALHO DOS PROFESSORES
}

\author{
TEACHERS' AUTHORITY AND THE COMPLEX MAKING OF THE COMMON: \\ TENSIONS AND CRITICISMS IN THE FAMILIES' INTERVENTION IN THE \\ WORK OF TEACHERS
}

\section{LA AUTORIDAD DOCENTE Y LA COMPLEJA FABRICACIÓN DE LO COMÚN: TENSIONES Y CRÍTICAS EN LA INTERVENCIÓN DE LAS FAMILIAS EN EL TRABAJO DE LOS PROFESORES}

Luís Gouveia

\section{RESUMO}

Com a massificação da escolarização, alunos oriundos de meios social e culturalmente mais diversificados protagonizam trajetos escolares mais prolongados. Sustentadas em diretrizes políticas transnacionais, estas mudanças ocorrem também no contexto de uma instituição escolar moldada pelo paradigma da eficácia escolar. Nesta nova conjuntura, os moldes tradicionais em que é exercida autoridade dos professores são colocados à prova. No quadro do conjunto das profundas mudanças políticas, sociais e organizacionais que marcam o sistema educativo nas últimas décadas, pretende-se neste artigo explorar diferentes sentidos críticos mobilizados pelos professores relativamente à relação com os pais/Encarregados de Educação - em que dimensões da atividade docente essa intervenção é mais suscetível de acontecer e que juízos críticos são mobilizados por estes profissionais.

PALAVRAS-CHAVE: Relação pais-professores. Autoridade docente. Tensões e críticas. Regimes de envolvimento na ação.

\section{ABSTRACT}

With the massification of schooling, students from socially and culturally more diversified backgrounds carry out longer school trajectories. Sustained in transnational political orientations, these changes also occur in the context of a school institution shaped by the paradigm of school effectiveness. In this new conjuncture, the traditional models in which teachers' authority is exercised are put to the test. In the context of a set of profound political, social and organizational changes that mark the educational system in the last decades, this article intends to explore different critical senses mobilized by teachers regarding the relationship with parents - in which dimensions of the teaching activity this intervention is more likely to happen and the critical judgments are produced by these professionals regarding them.

KEYWORDS: Parents-teachers' relationship. Teachers' authority. Tensions and criticism. Regimes of engagement in action.

\section{RESUMEN}

Con la masificación de la escolarización, alumnos oriundos de medios social y culturalmente más diversificados protagonizan trayectos escolares más prolongados. Sostenidas en directrices políticas transnacionales, estos cambios ocurren también en el contexto de una institución escolar moldeada por el paradigma de la eficacia

\footnotetext{
${ }^{1}$ Doutor em Sociologia - Universidade Nova de Lisboa (UNL) - Lisboa, Portugal. Investigador integrado no CICS.NOVA - Centro Interdisciplinar de Ciências Sociais da Universidade Nova de Lisboa (UNL) - Lisboa, Portugal. E-mail: Icgouveia86@gmail.com

Submetido em: 09/10/2017 - Aceito em: 04-03-2018
}

(C) ETD-Educação Temática Digital Campinas, SP $\quad$ v.20 $\quad$ n.2 $\quad$ p. $434-454 \quad$ abr./jun. 2018


escolar. En esta nueva coyuntura, los moldes tradicionales en que se ejerce la autoridad de los profesores se ponen a prueba. En el marco del conjunto de los profundos cambios políticos, sociales y organizacionales que marcan el sistema educativo en las últimas décadas, se pretende en este artículo explorar diferentes sentidos críticos movilizados por los profesores en relación a la relación con los padres/Encargados de Educación - en qué dimensiones de la actividad docente esta intervención es más susceptible de ocurrir y qué juicios críticos son movilizados por estos profesionales.

PALABRAS CLAVE: Relación padres-profesores. Autoridad docente. Tensiones y críticas. Regímenes de participación.

\section{A UBIQUIDADE DO PROBLEMA DA AUTORIDADE DOCENTE}

A sala dos professores, enquanto território central das sociabilidades dos docentes no espaço escolar, pode ser um palco privilegiado para observar e analisar juízos críticos elaborados por estes profissionais em torno de diversos aspetos relacionados com a sua atividade profissional (BARRÈRE, 2002). Área tipificada dos estabelecimentos de ensino, além dos diálogos que nele se desenrolam, a forma como este espaço é apropriado por estes profissionais e os objetos que o povoam podem dar-nos pistas em torno de elementos críticos que marcam o seu quotidiano. Ora, na sala dos professores de uma escola portuguesa onde tem lugar um trabalho de observação etnográfica ${ }^{2}$, a análise incide justamente sobre alguns dos objetos que nela marcam presença e que nos remetem para questões específicas do quotidiano docente. Uma imagem em particular, exposta à entrada de uma zona de convívio, destaca-se.

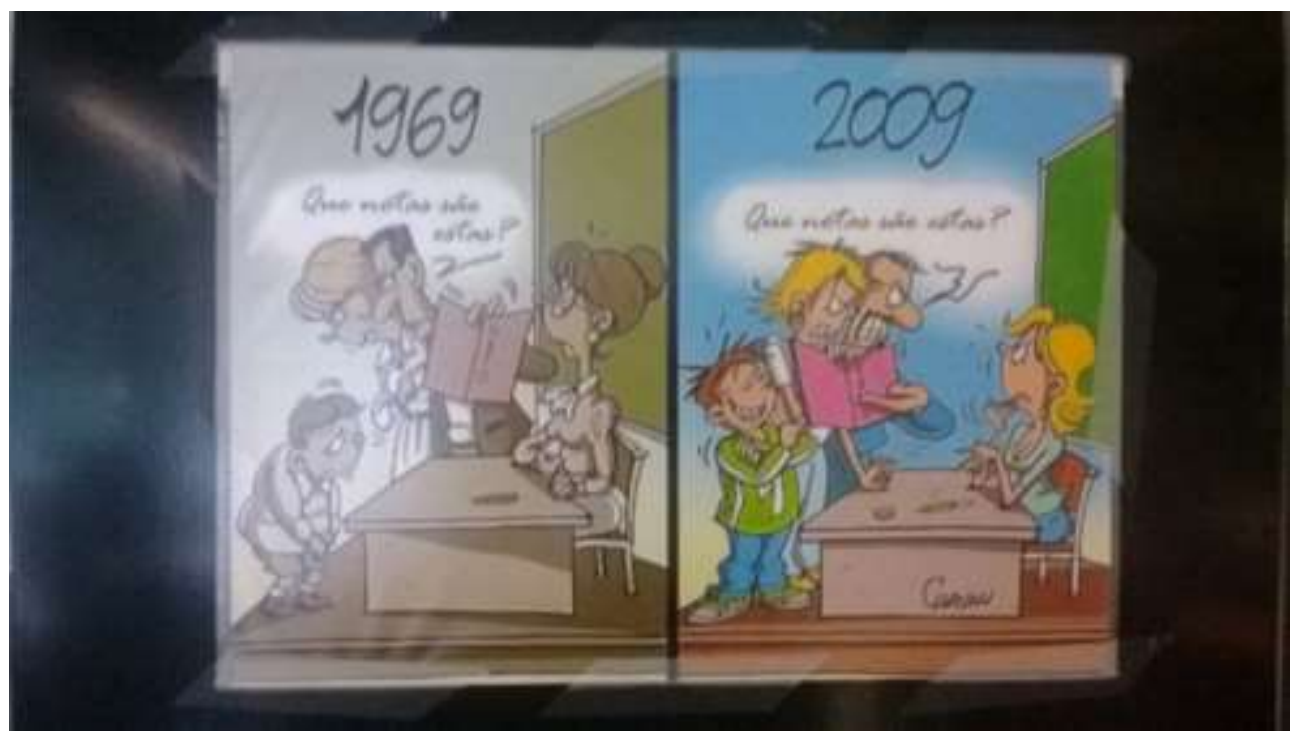

FIGURA 1

Fonte: registo da observação etnográfica (Escola B; Sala dos professores)

\footnotetext{
${ }^{2}$ Os dados apresentados neste artigo são recolhidos a partir de um projeto de investigação intitulado "Porque se mobilizam os professores? Representações coletivas e coordenações de ações públicas dos professores do Ensino Básico e Secundário em função dos juízos plurais sobre o que é um bom profissional de ensino num contexto de incerteza". O trabalho de campo assenta em 3 técnicas de recolha e análise de dados, entre as quais, a observação etnográfica. A descrição mais detalhada é realizada na nota de rodapé seguinte.
}

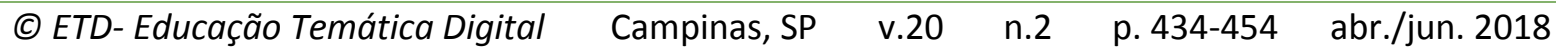


A imagem de um cartoon retrata uma situação de interação envolvendo uma professora um aluno e os respetivos pais, com algumas similitudes, mas em temporalidades distintas. Na primeira situação, que a legenda situa em "1969", o conhecimento das classificações (não satisfatórias) obtidas por parte do respetivo educando gera a exasperação dos pais direcionada ao educando, acabrunhado, e perante a postura esfíngica da professora. $\mathrm{Na}$ vinheta contígua, temporalmente situada 40 anos depois, a mesma questão é colocada pelos pais - "Que notas são estas?" -, feita num tom irado e inquisidor, mas dirigido agora à professora, que se apresenta amedrontada, em contaste com o semblante triunfante do educando.

Esta imagem, pretendendo fornecer uma visão satírica em torno de uma conjuntura reconhecível para os docentes do ponto de vista do relacionamento da tríade paisprofessores-alunos, remete para um elemento central nos juízos críticos produzidos por estes profissionais relativamente à sua atividade profissional: o da autoridade docente na relação com alunos, mas também na relação com os pais/Encarregados de Educação (EE). Efetivamente, a questão das dificuldades no relacionamento com estes atores surge frequentemente nos discursos dos professores quando se pronunciam em torno do seu quotidiano (RESENDE, 2010; SÁ, 2004). Se é sobretudo a partir dos anos 80 que se intensifica a produção sociológica em Portugal em torno da relação escola-família (SILVA, 2010), esta emergência surge contextualizada pelas políticas de descentralização que paulatinamente se desenvolvem no país, mas que seguem dinâmicas transnacionais (BARROSO, 2003), embora com significativas diferenças do ponto de vista das modalidades e da profundidade em que esta descentralização decorre (MAROY, 2008; DUTERCQ, 2005).

Parte integrante desta reorganização do funcionamento dos sistemas educativos são as reconfigurações da relação escola-família. Nomeadamente, à transferência de responsabilidades para os estabelecimentos de ensino enquanto unidades territoriais estão também acopladas orientações políticas no sentido de um maior envolvimento dos pais enquanto membros de uma mesma comunidade educativa ${ }^{3}$ (IDEM). Contudo, à parte destas novas orientações, e com efeitos concretos no quotidiano escolar, a relação entre a família e a escola não deixam de ser marcada por tensões e mal-entendidos comunicacionais (DUBET, 1997; THOLLOMBECK, 2009; PERRENOUD, 1987) entre os pais/EE e aqueles que são os principais agentes do trabalho de socialização realizado na instituição escolar: os professores. O propósito deste artigo é justamente explorar a questão dos focos de tensão e crítica, a

\footnotetext{
3 Estas dinâmicas transnacionais em matéria de orientação política são recontextualizadas em função da realidade e tradição política de cada país. Não sendo possível neste artigo proceder a uma descrição exaustiva, para maior detalhe em torno das especificidades das reformas educativas em Portugal (e respetivo quadro jurídico-normativo) e do envolvimento dos pais enquanto problema político, ver Sá (2004).
}

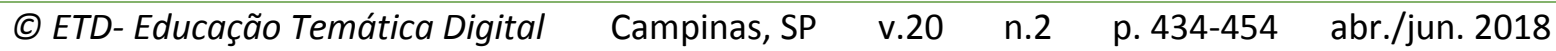


partir de diversas fontes de dados empíricos, e direcionada particularmente para as perspetivas daqueles profissionais de ensino ${ }^{4}$.

Num itinerário que se pretende que seja continuamente guiado através de excertos de entrevistas e observações etnográficas a professores, a incursão tem início, após um breve enquadramento em torno da problemática da relação pais-professores, nos juízos construídos pelos docentes desde a presença dos pais nos órgãos de gestão dos estabelecimentos de ensino até ao plano das interações quotidianas. São nomeadamente exploradas as principais causas que espoletam situações de tensão entre estes dois grupos de atores e as perspectivas críticas produzidas pelos docentes. Em segundo, é singularizada a questão da componente da educação, e o peso que assume na relação do professor com o discente no contexto atual (por contraposição à instrução), e as suas implicações (do ponto de vista crítico dos professores) quer ao nível das expectativas produzidas pelos pais relativamente à Escola, quer ao nível das suas repercussões no plano imagem social do professorado - nomeadamente, os possíveis dissonâncias com as conceções que os docentes produzem sobre o seu mandato e as relações de causalidade com os cenários de desvalorização social da profissão que surgem traçados. Somos conduzidos, por fim, aos diagnósticos aduzidos relativamente às causas mais remotas dessa mesma desvalorização e as mudanças que são evocadas como condição para uma revalorização do seu estatuto profissional. $\mathrm{O}$ último ponto do artigo releva a pluralidade compósita que está subjacente aos juízos e formas de envolvimento dos professores na relação com as famílias.

\footnotetext{
${ }^{4} \mathrm{O}$ trabalho de campo incide sobre 5 escolas do Ensino Básico e Secundário (equivalente ao Ensino Fundamental e Médio no Brasil, respetivamente) do sistema de ensino público português, com públicos escolares socialmente contrastantes. A escola " $A$ " situa-se num município a norte de Portugal, com alunos maioritariamente filhos de pequenos agricultores e empresários com baixas qualificações escolares. A escola " $B$ " situa-se no centro do município de Lisboa (a capital portuguesa) e alberga uma população estudantil socialmente diversa, registandose uma muito significativa presença de alunos de famílias carenciadas. A escola " $C$ " situa-se num município adjacente ao município de Lisboa e apresenta uma população estudantil onde predominam alunos oriundos de classe média. A escola " $D$ ", localizada no centro de Lisboa, conta com uma população escolar composta por significativos contingentes de alunos oriundos da classe média alta, registando-se em maior percentagem os pais ou encarregados de educação com habilitações ao nível do Ensino Superior. Por fim, a escola "E", situada num município do sul-interior de Portugal, apresenta um perfil de alunos maioritariamente oriundos de classes populares.

Ao todo, três técnicas de recolha e análise de dados são mobilizadas. Em uma discrição que se pretende sintética, em primeiro lugar, tem lugar a condução de entrevistas semidiretivas - ao todo, 40. Através de uma amostragem por quotas, são realizadas 8 entrevistas em cada escola, 2 por diferentes agrupamentos de disciplinas (Línguas, Ciências Sociais e Humanas, Ciências Experimentais e Expressões). Em segundo, tem também lugar a observação etnográfica em dois dos estabelecimentos de ensino que compõem a amostra (escolas $A$ e $B$ ). $A$ observação decorre em momentos informais (sendo privilegiada a sala dos professores), mas também em momentos de interação formal (espaços de acesso reservado, nomeadamente, salas de aulas e reuniões de Conselho de Turma). Por fim, o protocolo de trabalho de campo inclui ainda a aplicação de um questionário por cenários. $\mathrm{A}$ apresentação de resultados obtidos a partir desta técnica em particular fica de fora do presente artigo.
} 


\section{DA DIFÍCIL COLABORAÇÃO À EDUCAÇÃO COMO ELEMENTO CORROSIVO DA AUTORIDADE}

A massificação e a descentralização do sistema educativo estão na base de profundas transformações no quotidiano docente (RAYOU; VAN ZANTEN, 2004). Uma das vertentes dessas mudanças prende-se justamente com o propósito de um maior envolvimento dos pais no processo educativo, enquanto componente integrante das políticas de progressiva transferência de responsabilidades para os estabelecimentos de ensino (MAROY, 2008). Essa maior colaboração enquanto membros de pleno direito de uma mesma comunidade educativa assume a forma, desde logo, de constituição de novos organismos, como é o caso das Associações de Pais, e de uma crescente presença institucional destes atores nos órgãos de gestão dos respetivos estabelecimentos de ensino (STOER; SILVA, 2005).

Estas mudanças organizacionais inserem-se numa dinâmica de reequacionamento dos processos de escolarização das famílias e que ocorre num quadro de expansão dos níveis de escolaridade, cujas causas recaem sobre três grandes fatores e que fundamentam as políticas do Estado para uma expansão generalizada dos níveis de escolaridade da população até aos patamares mais avançados do sistema educativo: o princípio de igualdade de oportunidades (enquanto condição para a democratização das sociedades); a escolarização generalizada enquanto veículo de mobilidade social e princípio de hierarquização social mais legítimo próprio de sociedades democráticas; e, por último, uma relação estreita entre escolarização e desenvolvimento económico e social promovida pelas teorias económicas do capital humano que progressivamente se incrustam no discurso político (VIEIRA, 2003).

Ora, neste quadro de expansão quantitativa do sistema de ensino, os moldes de relacionamento dos pais com os processos de escolarização alteram-se no contexto de uma instituição escolar enquanto instância definidora dos destinos sociais e no contexto de uma rede escolar com uma oferta curricular mais diversificada entre as escolas. Nomeadamente, sendo diplomas escolares uma via de ascensão social, a frequência escolar adquire uma componente estratégica e de mobilização das famílias (DIOGO, 2008; VAN ZANTEN, 2009).

Por outro lado, a crítica que emerge nos anos 70 relativamente a modelos sociais homogeneizadores, burocráticos e hierarquicamente estruturados estende-se também à instituição escolar. O princípio de igualdade de oportunidades enquanto programa de justiça estruturador do funcionamento do sistema educativo (DEROUET-BESSON, 2009) - sustentado na unificação de programas, currículos, etc. - é questionado, com as denúncias das desigualdades de desempenho entre estabelecimentos de ensino (através da prova estatística) a desempenhar um importante papel. Estas operações críticas estão na base das políticas de transferência de responsabilidades para unidades territoriais - autarquias e estabelecimentos de ensino - tendo em vista uma maior adequação da oferta curricular e do trabalho escolar à diversidade dos públicos (IDEM).

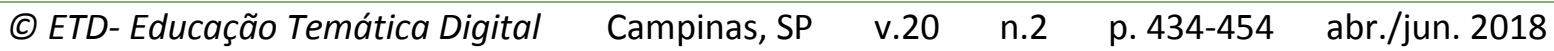


Parte integrante destas políticas de descentralização, autonomização e responsabilização está igualmente a implicação e participação ativa dos potenciais interessados - não apenas as autarquias locais e agentes económicos do meio envolvente de cada escola, mas também as famílias dos alunos que frequentam os estabelecimentos de ensino. Associada a esta dinâmica de reconfiguração da relação escola-família estão também as políticas de constituição de um mercado escolar e que inauguram um novo posicionamento dos pais com os estabelecimentos de ensino enquanto clientes (MONTANDON, 1987).

Ora, neste novo quadro político e organizacional que incita a uma maior colaboração escola-família - e sendo esta relação representada nos discursos dos professores sobretudo pela interação com o grupo dos pais/EE - nos discursos dos docentes não deixa assomar frequentemente a questão das dificuldades na relação com estes atores, e que surge desdobrada em diferentes dimensões. Num primeiro plano, esta presença institucional, nos moldes em que ela evolui nos anos mais recentes em Portugal (e na linha de orientações de política educativa reproduzidas em outros países) (SÁ, 2004), não deixa de ser objeto de críticas entre os professores. É o caso de uma professora de Inglês ${ }^{56}$ :

\begin{abstract}
"E foi isso que essa reforma trouxe: professores em minoria, quem manda são os pais, quem manda são as "forças vivas da sociedade", esses é que mandam... Quando eu penso que tenho no meu Conselho Geral... Faço parte dele; só vou lá buscar guerras, conflitos, etc. Não me importa; é o meu espaço, onde eu posso fazer alguma diferença... Mas temos dois alunos, temos dois Encarregados de Educação, três "forças vivas", três vereadores... Veja como isto é possível! " (E1; escola A; professora de Inglês; 32 anos de experiência profissional)
\end{abstract}

É o novo figurino organizacional que sai da última reforma da lei da gestão dos estabelecimentos de ensino ${ }^{7}$ em vigor - neste caso em particular, no sentido do reforço da

\footnotetext{
${ }^{5}$ Os dados das entrevistas recolhidos (ver notas de rodapé anteriores) inserem-se num projeto de investigação mais abrangente no seu objeto e que se centra nos discursos e lógicas atuantes dos professores relativamente a várias dimensões da sua atividade profissional - entre as quais a relação com os pais/Encarregados de Educação. Nessa medida, é apenas considerada a perspectiva dos docentes em torno da problemática abordada no presente artigo, sendo inexistentes dados empíricos relativos a discursos de pais/EE.

${ }^{6}$ Os dados recolhidos de entrevistas e observação etnográfica são analisados à luz da abordagem teórica comumente designada de Sociologia Pragmática. Tendo como propósito aceder à multiplicidade de formas de racionalidade postas em prática pelos atores em diversos contextos, a ação é entendida a partir das modalidades a partir das quais os atores se envolvem na ação, nas formas de coordenação com os outros e consigo mesmos. Estas diferentes modalidades de envolvimento constituem diferentes regimes de envolvimento na ação, sendo cada regime convocado em função do juízo realizado pelo ator em cada situação (BOLTANSKI; THÉVENOT, 2001 [1991]; THÉVENOT, 2006). É através deste complexo corpo teórico-conceptual que se pretende justamente compreender em que diferentes regimes de envolvimento na ação os professores assentam as suas práticas e lógicas discursivas (Resende, 2003; 2010). Neste caso em particular, o objetivo é o de analisar os regimes de ação mobilizados em torno da relação com os pais/EE.

${ }^{7}$ No quadro das orientações políticas em benefício de uma autonomização dos estabelecimentos de ensino e de maior envolvimento dos pais e outros atores nos respetivos estabelecimentos de ensino, a reforma de 2008 do regime de autonomia, administração e gestão dos estabelecimentos de ensino do pré-escolar ao ensino secundário (D-L no 75/2008), entre outras medidas, cria o Conselho Geral, que tem como função a aprovação das regras do regulamento interno da respetiva escola, projeto educativo e plano anual de atividades, e no qual "têm representação o pessoal docente e não docente, os pais e encarregados de educação (e também os alunos,
}

$\begin{array}{llllll}\text { (C) ETD-Educação Temática Digital } & \text { Campinas, SP } & \text { v.20 } & \text { n.2 } & \text { p. 434-454 } & \text { abr./jun. } 2018\end{array}$


presença e influência dos Encarregados de Educação no Conselho Geral, juntamente com outros elementos externos à escola - que é perspetivado pela entrevistada, ao colocar os professores em minoria naquele que é o órgão máximo de gestão da escola, como uma inversão de forças entre as partes envolvidas e com efeitos do ponto de vista da sua área de jurisdição profissional (ABBOTT, 1988) ("quem manda são os pais"). Esta nova realidade organizacional, objeto de indignação da inquirida, é percecionada como simultaneamente sintoma e consequência de uma erosão da autoridade da figura do professor no quadro de uma realidade escolar mais aberta ao meio envolvente e, com isso, mais permeável e exposta aos juízos de atores externos(LANTHEAUME ; HÉLOU, 2008).

Mas além do reforço da presença institucional através da emergência dos sistemas de participação parental (SILVA; STOER, 2005), é sobretudo no plano das interações que ocorrem ao longo do ano letivo que a relação entre pais e professores se desenvolve (MONTANDON, 1987), sendo que neste contacto que entram em jogo uma complexa dinâmica de expectativas entre pais e professores relativamente às funções a desempenhar por cada uma das partes (SÁ, 2004). Por um lado, na base desta dinâmica está desde logo a divergência de entendimentos na forma como cada aluno é perspetivado. É o que ressalta do discurso da mesma docente:

\footnotetext{
"E depois vem um Encarregado de Educação que diz "Eu não gostei da forma como tratou o meu filho!" Porque o filho deles é um... é só aquele, não está inserido num contexto. Para mim é um aluno, no meio de muitos e as pessoas esquecem-se disso e chegam aqui e exigem, exigem e exigem." (E1; escola $A$; professora de Inglês; 32 anos de experiência profissional)
}

Como surge implicitamente na narrativa da entrevistada, a atenção às particularidades do respetivo educando por parte dos Encarregados de Educação pode conflituar com a forma como os professores perspetivam o aluno, enquadrado num coletivo e estando as formas de relacionamento tendencialmente orientadas pelo princípio cívico de igualdade de tratamento (BOLTANSKI; THÉVENOT, 2001 [1991]) e direcionadas para o desenvolvimento de dinâmicas de trabalho coletivo (MONTANDON, 1987).

Num outro plano, a função dos pais/EE no acompanhamento do trabalho dos alunos surge como elemento frequentemente criticado pelos professores, expondo as expectativas do ponto de vista do seu envolvimento no trabalho escolar do respetivo educando (SÁ, 2004). Num diálogo captado na sala de professores, dois professores discutem o problema de aproveitamento escolar dos alunos de uma turma que têm em comum. O diagnóstico

no caso dos adultos e do ensino secundário), as autarquias e a comunidade local [...]" (idem: 2342). Como descrito no preâmbulo, esta reconfiguração visa "reforçar a participação das famílias e comunidades na direção estratégica dos estabelecimentos de ensino", promovendo a "abertura das escolas ao exterior e a sua integração nas comunidades locais" - constituindo um mecanismo de "prestação de contas da escola relativamente àqueles que serve" (idem: ibidem).

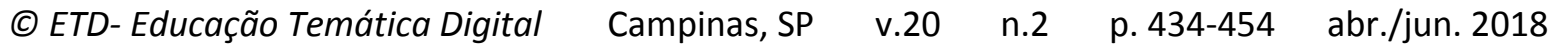


pessimista que traçam abarca também de forma mais explícita, quando o diálogo a incide sobre um aluno em particular, a função de acompanhamento do trabalho escolar por parte dos pais:

P1: A A__ vai chumbar por faltas. Andam ali o L__ e a $A$

P2: Eu passo a vida a fazer exercícios. Mas depois, 'Ah, professora, e agora aqui?'

P1: Não querem...

P2: Nas aulas práticas não fazem nada. E depois querem que as médias aumentem...

P1: Só se fosse com o chicote, a fazer os exercícios...

P2: Os nossos miúdos não vão a lado nenhum...

P1: Ainda há pouco estive com o pai do $\mathrm{N}$ Não vai fazer nada. E o pai diz-me

"Ah, ele é muito parecido comigo..." $\mathrm{O}$ facto de ele dizer isso não resolve o problema do filho! Um pai, dizer isto!?

(Registo de observação; sala dos professores; escola B)

Além do problema da obtenção de aproveitamento, e particularmente da ausência de esforço e trabalho ("nas aulas práticas não fazem nada") enquanto valores engrandecidos pela instituição escolar e que fundamenta os juízos críticos que ambos os docentes constroem relativamente aos alunos da turma em questão, estas críticas implicitamente transferem-se também para a função educativa a desempenhar pelos pais. Nomeadamente, o exemplo da resposta do Encarregado de Educação por um dos interlocutores (P1) surge como particularmente objeto de perplexidade (“Um pai, dizer isto!?”) e apontado tacitamente como parte do problema. Particularmente em contextos de ensino onde os contextos familiares dos alunos são marcados por carreiras escolares também elas já caracterizadas por baixos níveis de escolaridade ou por insucesso, estas trajetórias são suscetíveis (mas sem ser necessariamente ser um fator determinante) de ter repercussões do ponto de vista das expectativas dos pais relativamente ao processo de escolarização dos educandos ou no acompanhamento do trabalho escolar (DIOGO, 1998).

No entanto, é a questão da indisciplina que parece sobressair nos discursos dos professores como um elemento particular que desencadeia situações de tensão entre professores e pais enquanto problema em si, mas também enquanto causa do insucesso escolar. O excerto de uma entrevista a uma professora de Matemática dá conta dessa perspetiva frequentemente veiculada pelos docentes:

“[...] os pais exigem muito que o professor atue e quando nós dizemos que há uma indisciplina na sala de aula a culpa é sempre do professor. Depois, se o professor intervém com o filho daquele pai, aí o pai já diz que a culpa não é do filho, pode ser dos colegas... Portanto, tenta desculpabilizar o filho. [...] É muito difícil convencer os pais que o professor fez o melhor que podia e sabia para resolver situações de indisciplina ou situações que justifiquem algum insucesso. A indisciplina assim põese não como um problema em si, mas como uma causa do insucesso. E aí é que os pais ficam muito preocupados. O professor tem de justificar por ele e pelos colegas quando é diretor de turma. Os pais estão cada vez mais interventivos." (E22; escola C; professora de Matemática; 30 anos de experiência profissional) 
No quadro das expectativas que os pais produzem relativamente ao percurso escolar dos filhos enquanto via que determina o destino social dos mesmos (VIEIRA, 2003; DIOGO, 1998), a intervenção em situações de indisciplina associada aos problemas de desempenho escolar (constituindo simultaneamente causa e consequência dos mesmos) parecem surgir no centro das situações de confronto, e em que a intervenção dos Encarregados de Educação assume a forma de imputação de situações de indisciplina ao professor e consequente desculpabilização do educando - constituindo esta conduta protetora uma forma de entrave ao próprio exercício da ação disciplinar dos professores.

Ora, se a indisciplina associada ao desempenho escolar assume centralidade como fator propiciador de momentos de confronto e tensão entre as duas partes, nestes juízos críticos elaborados pelos professores o problema parece ancorar-se, por sua vez, num mais amplo problema, a montante, relativo à autoridade do professor. É o que sobressai do discurso uma professora de Português:

"O professor já foi uma autoridade, agora é olhado como um igual, na minha opinião. É quase igual. Eles dizem qualquer coisa, mas muito pouco. Na maioria das situações eles acham que os filhos é que tem razão. Põem-se sempre do lado dos filhos, é o que eu tenho reparado." (E4; escola A; professora de Português; 22 anos de experiência profissional)

A questão da intervenção, nos moldes que ela é feita, naquilo que é descrito como uma atitude protetora em relação ao educando e que pode resvalar para situações de confronto com a figura do professor, é entendida como o reflexo de uma crise de autoridade do professor (LANG, 2001) e cujas consequências na relação com os pais estendem-se igualmente à relação com os alunos - materializando-se em lógicas relacionais em que o professor, "olhado como um igual", depara-se com uma inversão de grandezas em que deve assentar a ordem escolar na relação docente-discente (RESENDE; CAETANO, 2013). Esse mesmo enquadramento a partir da questão da autoridade docente é acompanhado por outra professora:

\footnotetext{
"É importante que os pais acompanhem a vida escolar dos filhos. É o que a escola pretende. Agora, acompanhem como? Não é vir só cá "Ah, mas porque é que o meu filho teve 14,1 e não teve 14,2?"; "Ah, o professor fez uma participação do meu filho. Mas o que é que ele fez?" Essas pessoas pensam que estão a ajudar os filhos, mas estão simplesmente a dar mais força para que os filhos tenham um comportamento cada vez menos adequado à sala de aula. Eles pensam "Se fizerem uma participação a minha mãe até vem cá..." E se encontrar um Diretor de Turma que não esteja muito seguro, até lhe dá razão." (E37; escola E; professora de Física e Química; 33 anos de experiência profissional)
}

Não descartando o envolvimento dos pais e Encarregados de Educação no processo educativo enquanto pressuposto na relação entre as instituições escola e a família, o que surge criticado no discurso da entrevistada é o modo como essa participação na prática decorre. Neste caso concreto, a contestação das classificações surge como elemento que 
pode ter como consequência última minar a relação de forças entre as duas figuras, com reflexos sobre o respeito do aluno na relação com a figura do professor - logo, nesse sentido, um fator de erosão da autoridade do docente.

Por outro lado, se problema da indisciplina surge como um elemento central nas observações críticas que os professores elaboram do ponto de vista da relação com os alunos, estas críticas são acompanhadas pela alusão ao que são entendidas como ineficiências no trabalho de educação no contexto familiar e que constituem um elemento particularmente constrangedor do trabalho de qualificação (RESENDE, 2010) que os professores procuram realizar junto dos alunos. Nomeadamente, ao trabalho de instrução e formação acrescentase o trabalho de educação como pressuposto ou etapa prévia. É esta perspetiva que ressalta do discurso de uma professora de Alemão:

\footnotetext{
"Porque hoje em dia, e com a mudança do público-alvo que nós temos sofrido, e daí que isso implica a mudança de estratégias de ensino, nós neste momento, nesta altura da sociedade, nós não formamos só. Nós também educamos. O simples chapéu na cabeça; o simples estar sentado na cadeira, que há alunos que não sabem; o respeito pela autoridade... Nós neste momento, a mudança na sociedade é tal que nós também temos que ser educadores. Também temos que fazer a fusão. Também somos nós que passamos mais tempo com os alunos. Isso é verdade. Entre o chegar a casa e tomar banho, passa-se o dia. Mas nós temos que ser um bocadinho de tudo. Psicólogos, ouvintes, aconselhadores... tudo." (E32; escola D; professora de Alemão; 18 anos de experiência profissional)
}

As mudanças verificadas nos públicos escolar, e que decorrem da massificação da escolaridade, e consequente maior diversidade do ponto de vista dos contextos sociais e culturais de origem (ALMEIDA ; VIEIRA, 2000), trazem consigo implicações do ponto de vista das formas de relacionamento com a figura do discente. Nomeadamente, ao professor é requerido, com mais intensidade, um trabalho de acomodação do aluno à gramática do espaço da sala de aula (RESENDE, 2010), transposta para os gestos ("estar sentado na cadeira") e modos de se apresentar ("o simples chapéu na cabeça"), até ao "respeito pela autoridade" inerente à figura do professor. Esta inculcação de regras, cuja responsabilidade recai sobre o espaço familiar enquanto condição sine qua non para um trabalho do professor focado eminentemente na instrução e formação (VIEIRA, 2003), é igualmente aludida por um docente de Matemática:

\footnotetext{
"A escola deve servir em primeiro lugar, no seu contexto mais geral, para formar e educar. Formar mais do que educar. O educar é um complemento do que se faz em casa. A escola não se pode demitir das suas funções de educar, embora a sua função principal é formar. Um aluno com uma base familiar regular já tenha as suas regras que a escola não deveria transmitir, mas sabemos que por motivos vários devido à sociedade em que todos vivemos, não há na família aquele equilíbrio que permita que um aluno esteja preparado, com regras em casa, para estar na escola a ser apenas formado. Quando eu digo formado digo no sentido de conceitos de ensino que a escola administra. É essa para mim a função principal da escola." (E25; escola D; professora de Matemática; 24 anos de experiência profissional)
} 
Se é na instrução, enquanto transmissão dos conteúdos das diferentes áreas disciplinares, que nesta composição de ordens de grandeza (RESENDE, 2010) construída pelo entrevistado reside a "função principal da escola", o que é justamente denunciado é a crescente importância que a educação assume presentemente no relacionamento com os alunos. As mudanças sociais e as insuficiências no trabalho educativo realizado no contexto familiar - fruto também de mudanças sociais e com reflexos na estrutura familiar (MONTANDON, 1987) - é apontado como um fator particular de constrangimento à construção uma plataforma de interação com a figura do discente necessária para um trabalho eminentemente centrado na transmissão de conteúdos disciplinares. É justamente essa questão que é levantada por outra professora quando se pronuncia sobre as funções que compõem o mandato da instituição escolar:

\footnotetext{
"A escola deve ensinar, principalmente, enquanto que neste momento temos uma escola com uma grande responsabilidade que é educar os alunos. Mas eu acho que o grande papel da escola deve ser educar os alunos. Se os alunos não tivessem tantos problemas de indisciplina, era mais fácil a tarefa de ensinar. Muitas vezes é-nos exigido é a tarefa de educar, que vai roubar muito tempo dentro da sala de aula à outra tarefa que eu acho que é a tarefa essencial da escola." (E22; escola C; professora de Matemática; 30 anos de experiência profissional)
}

Se na composição de ordens de grandeza (BOLTANSKI ; THÉVENOT, 2006 [1991]), a vertente da instrução constitui a tarefa "essencial" da escola e do professor, ela embate justamente num contexto de ensino onde a educação, em particular, a intervenção sobre a indisciplina dos alunos enquanto elemento disruptivo do trabalho de formação científica e transmissão de conhecimentos da respetiva área disciplinar, se situa no âmago do seu trabalho de qualificação (RESENDE, 2010). Ora, num contexto educativo marcado por uma diversidade de contextos de ensino, conformando uma realidade profissional internamente segmentada (RAYOU ; VAN ZANTEN, 2004) a tarefa de polimento de condutas pode surgir como particularmente central nos estabelecimentos de ensino marcados por públicos estudantis socialmente mais desfavorecidos. O discurso de uma docente de Português que, além de exercer a atividade numa escola que acolhe alunos oriundos de contextos sociais tendencialmente mais desfavorecidos (ver nota 3 ), leciona em turmas do ensino profissional - cuja tipologia de discentes que acolhe implica um trabalho de exercício da autoridade também tendencialmente mais complexo (IDEM) -, ilustra precisamente esta ideia:

\footnotetext{
"Eu tive cursos profissionais nesta escola em que os alunos entravam no 10 dia de aulas aos pulos e berros na sala de aula e não sabiam estar numa sala de aula. E eu levava todo o 10 período, e às vezes Janeiro ainda, a tentar fazer deles alunos normais. $\mathbf{O}$ saber ser aluno, o saber estar na sala, que são valores que nos temos de implementar à partida, tentar educá-los minimamente... Porque eles vinham completamente desembestados. E eram alunos com problemas familiares... É por isso que eu digo que a família está na base. Se a família se preocupa com o aluno, ele chega aqui educadinho, pronto a aprender." (E36; escola E; professora de Português; 40 anos de experiência profissional)
} 
O problema das incivilidades (GAYET-VIAUD, 2009) no comportamento dos alunos e o trabalho reparador de condutas que é requerido aos professores surge nos juízos críticos dos professores a par com a questão das expectativas que são produzidas relativamente ao que ambas as partes entendem que devem ser as funções do professor. Nomeadamente, 0 problema do trabalho de educação surge acoplado ao que no discurso dos docentes surge frequentemente como um problema de demissão dos pais da tarefa educativa. É o que ressalta do discurso de uma docente entrevistada, da mesma área disciplinar, abertamente crítica à realidade que identifica no sistema educativo:

\begin{abstract}
"No sistema educativo, os pais estão a demitir-se das suas funções, completamente. Os pais demitem-se das funções de educadores. Inclusivamente, vimos ontem na televisão as escolas a fechar por falta de professores e os pais a dizerem "O que é que eu vou fazer agora aos meus filhos?". Portanto, hoje a escola, pela maior parte dos encarregados de educação, é encarada como o depósito dos filhos." (E10; escola B; docente de Português; 35 anos de experiência profissional)
\end{abstract}

Sem afastar necessariamente a questão da educação enquanto elemento que integra as suas formas de agir na relação com os alunos, são sobretudo os possíveis efeitos que essa expectativa pode representar para o estatuto social do professor que surgem de forma mais ou menos evidenciada nos discursos críticos (RESENDE, 2010). Efetivamente, os juízos críticos dos professores orientam-se frequentemente para o que interpretam como uma visão da escola como depósito (SÁ, 2004), e as suas possíveis tensões com os entendimentos que estes profissionais constroem em torno da composição de funções que enforma o seu mandato enquanto profissionais de ensino. É justamente esta perspetiva que surge patente no discurso de um docente de Educação Física:

\footnotetext{
"Um professor agora não é só professor da sua disciplina. [...] E quase, no sentido figurativo, somos 'pau para toda a obra'; temos de estar preparados para tudo, para um conjunto de variedade de funções, muitas delas para as quais não se sentem diretamente vocacionados [...] E por isso hoje em dia o professor tem de estar preparado para ser professor, psicólogo, educador, pai... Tudo e mais alguma coisa." (E30; escola D; professor de Educação Física; 15 anos de experiência profissional)
}

A visão expressa pelo entrevistado da figura do professor como pau para toda a obra, no quadro de uma crescente complexificação das funções que recaem sobre a sua atividade (LANTHEAUME, 2006), deixando o trabalho docente de estar circunscrito às atividades instrutivas associadas à respetiva área disciplinar ("não é só professor da sua disciplina"), encontra também eco nos discursos espontâneos produzidos por estes profissionais no seu quotidiano. Ora, é igualmente a questão da perceção da escola como depósito enquanto elemento ostensivo de crítica dos docentes na relação com os pais e Encarregados de Educação que ressalta de um diálogo captado numa sala de professores. Uma funcionária (auxiliar de ação educativa) entra na sala informando uma das docentes presentes da situação de duas alunas que são intercetadas a sair da escola fora do horário de saída regulamentado, solicitando a intervenção da Diretora de Turma no sentido de contactar os respetivos

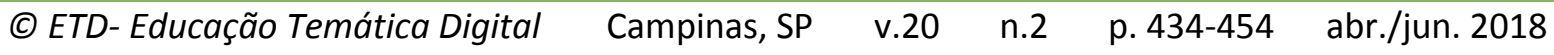


Encarregados de Educação. A situação espoleta um conjunto de comentários entre três outros professores presentes, aludindo à sobrecarga que estas novas responsabilidades representam para o corpo docente:

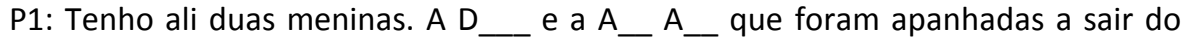
portão das traseiras. lam fugir da escola, iam-se embora. O Sr. J_ apanhou-as mais uma do 8‥ Elas estão ali. Eu fiquei com o cartão delas, mas queria que tu visses. Eu disse "Vou falar com a Professora $S$ e ela provavelmente vai falar com os Encarregados de Educação".

P2: É assim, da não consigo contactar. Aliás, essa $D$ está em risco de abandono. $\mathrm{Da} \mathrm{A}_{\text {__ }}$, também não consegues falar com ela. Isto é daquelas coisas... A gente tem que andar atrás deles...

[P1 e P2 saem da sala de professores]

P3: Isto é um inferno! Esta turma é um inferno vivo! Coitada... A nossa turma está cheia de problemas, mas não é nada disto; é anos-luz disto! Claro que são miúdos que estão cheios de... Uns de mimo, outros de algum sofrimento... Tenho situações muito diversas. Mas não é isto! Isto é alunos que estão sempre a fazer asneiras. Não saíste de uma e já estás noutra. Isto é um inferno, não se pode viver assim! Os pais têm que tomar conta!

P4: Os pais demitem-se... Demitem-se da parte deles.

P3: Mas a escola não consegue substituir os pais... Os miúdos é para estarem na escola e não chatearem.

P3: Isto é uma carga para o Diretor de Turma... É uma loucura!

P4: Qual é a turma dela?

P5: É o 7ọD.

P3: Isto é uma sobrecarga... As pessoas não têm noção, quem não passa por isto não têm noção. E eu estou a falar e nunca fui diretora de turma de uma turma assim! Isto é uma sobrecarga para uma pessoa, até emocionalmente. Não há ninguém que sobreviva com sanidade a uma coisa destas!

(Registo de observação etnográfica; escola B; sala dos professores)

São patentes as observações críticas que a situação das alunas suscita entre os professores e que remetem para a questão das novas obrigações que o contexto escolar atual acarreta para os docentes. $\mathrm{O}$ acolhimento das novas coortes de alunos que marcam presença na escola de massas acarreta um incremento do trabalho de monotorização para os professores que se estende para além da relação pedagógica no contexto de sala de aula e que é frequentemente gerador de perplexidades junto destes profissionais de ensino ("A gente tem que andar atrás deles..."). A "sobrecarga" que esta nova realidade estudantil acarreta para os docentes surge, por outro lado, intimamente ligada às demandas quanto às funções que a família e os Encarregados de Educação devem desempenhar no que concerne ao trabalho de educação ("Os pais têm que tomar conta!"; "a escola não consegue substituir os pais..."). Se a importância de lógicas proximidade (THÉVENOT, 2006) nas formas de

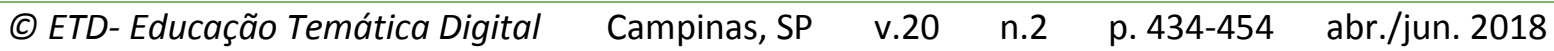


relacionamento com os alunos parece ser acolhida por significativas franjas de professores como uma importante acomodação do professor no contexto de uma escolaridade massificada (BARRÈRE, 2002; VAN VANTEN, 2001; 2004), este excerto é também ilustrativo do mal-estar manifestado pelos professores relativamente às responsabilidades fora da componente letiva que pendem sobre os professores e que são geradores de um profundo desgaste ("Isto é uma sobrecarga para uma pessoa, até emocionalmente") (LANTHEAUME ; HÉLOU, 2008). A perspetiva da escola como depósito dos alunos ("Os miúdos é para estarem na escola e não chatearem"), pendendo sobre os professores a responsabilidade de atuar sobre o conjunto de contrariedades de uma população estudantil cuja adesão ao trabalho escolar não é espontânea (num trabalho que se estende muito para além da relação estritamente pedagógica em sala de aula), é particularmente vista pelos professores como fonte potencial de desvalorização do seu estatuto profissional e de desvirtuamento da atividade, com efeitos nocivos sobre o que entendem ser a matriz do mandato e licença profissional do ofício docente (RESENDE, 2010; ABBOTT, 1988; HUGHES, 1985).

\section{RESPEITO E O PROBLEMA DA IMAGEM SOCIAL DA PROFISSÃO}

Além das tensões e problemas comunicacionais que são relevados, os olhares críticos dos professores não deixam igualmente de se orientar para aquilo que entendem ser fatores mais profundos que contribuem para um cenário de perda de autoridade do professor, e com reflexos, tanto na relação com os pais/EE, como com a figura do aluno. É nomeadamente a perspetiva de uma desvalorização social da profissão que parece surgir com particular frequência enquanto problema profundo e enraizado a montante. É o que ilustra o próximo excerto de uma entrevista realizada a uma professora de Português quando reflete sobre os problemas que deteta atualmente no sistema de ensino:

\footnotetext{
“Mas eu penso que a desvalorização social será dos maiores problemas. [...] Temos muitos pais que colaboram connosco, que de facto ajudam e que percebem que o nosso trabalho é um trabalho conjunto. Mas também temos tido problemas com pais que pensam que participar é criticar negativamente e isso vem também do facto de a sociedade valorizar menos a profissão. Portanto, está tudo interligado." (E19; escola C; professora de Português; 30 anos de experiência profissional)
}

Se a docente não questiona o princípio de envolvimento dos pais no processo educativo, é o que entende ser uma postura conflituosa e adversarial que denuncia. No diagnóstico que faz, é a menor valorização social da profissão no contexto atual que surge como elemento preponderante para enquadrar e compreender aquilo que entende ser uma postura de permanente crítica ("criticar negativamente") por parte dos pais e Encarregados de Educação.

No caso dos docentes cuja atividade se realiza em contextos escolares mais desfavorecidos do ponto de vista da composição social da sua população estudantil (RAYOU ; VAN ZANTEN, 2004), as situações de indisciplina são também enquadradas na questão da coerência do ponto de vista da política disciplina dos estabelecimentos de ensino, com 
consequências igualmente do ponto de vista da autoridade do professor. O discurso de uma professora de Inglês, docente num contexto escolar periférico (VAN ZANTEN, 2001), ilustra a perceção da impunidade como fator que mina a autoridade do professor:

\begin{abstract}
"[...] os meninos vivem numa redoma. Digo muitas vezes [...] "Vocês aqui na escola comportam-se assim porque é o único sítio onde podem gozar os adultos. $O$ único. Vocês em casa não podem fazer isso porque os vossos pais não permitem; cá fora não podem fazer isso porque levavam. Aqui é o único sítio onde impunemente podem gozar um adulto." É verdade! É o único sítio onde eles podem, não lhes acontece nada. Vão para casa um dia ou dois...? Oh, porreiro! E vem o Encarregado de Educação... Uns vêm-nos insultar, outros dizem assim: "Por favor, faça qualquer coisa que eu não sei já o que fazer com ele!" (E1; escola A; professora de Inglês; 32 anos de experiência profissional)
\end{abstract}

Se a falta de assertividade do ponto de vista da aplicação das sanções disciplinares é exatamente apontada pela docente como um elemento de fragilização da autoridade do professor no espaço escolar, a este fator junta-se a extensão do problema da indisciplina ao binómio professor-pais. Por um lado, os problemas de incivilidade nos alunos são agravados por posturas protetoras ou mesmo de hostilização por parte de pais/EE ("vêm-nos insultar"); noutros casos, pela assunção de incapacidade de intervenção junto dos respetivos educandos. Este complexo panorama que traça traduz-se no paradoxo que a inquirida observa da escola enquanto espaço onde a relação de grandezas entre os dois seres em questão - o professor enquanto representante do adulto e, logo, representante de um estado de maior grandeza por comparação com a figura do aluno - é subvertida (BOLTANSKI ; THÉVENOT, 2006 [1991]; RESENDE ; CAETANO, 2013), algo que não encontra paralelo em nenhum outro espaço ou contexto ("[a escola] é o único sítio onde podem gozar os adultos").

Ora, esta questão da valorização social que é colocada como um problema central do quotidiano profissional docente conduz a diagnósticos onde é levantada justamente a importância de reformas no sistema educativo e na carreia docente que permitam um engrandecimento da profissão (RESENDE, 2003). É o caso de um professor Educação Visual que, traçando um mesmo cenário de desvalorização da profissão, entende que o problema passa pela lassidão nos critérios de admissão (e consequentes efeitos na imagem social dos professores):

\footnotetext{
"Eu acho que é necessário investir bastante de facto nos professores. Haver processos bastante rígidos de seleção. Não sou contra as provas de ingressos para professores; antes pelo contrário. [...] Devia basear-se nas classificações. Acho que as pessoas saídas das Faculdades com notas mais altas, essas é que deviam ser professores, porque tinham conhecimento para isso. Deviam ser dadas carreias dignas da sua função e um estatuto social digno da sua função. Acho que isso ultrapassaria... O termos bons profissionais - e bons profissionais não quer dizer com isso, não quero dizer bons pedagogos... São pessoas munidas de bons conteúdos científicos e transversais, que pudessem estar à frente da escola e estar à frente das disciplinas. $E$ isso iria incutir nos alunos um maior respeito, nos pais $\mathbf{e}$ na sociedade. [...] E com carreiras, progressões e bem remuneradas, e com regalias, como já houve, eu penso que isso poderia edificar a profissão." (E40; escola E; professor de Artes Visuais; 25 anos de experiência profissional)
} 
Num contexto de massificação da escolarização no quadro da evolução do sistema educativo português nas últimas décadas (ALMEIDA ; VIEIRA, 2000), ao qual corresponde também um incremento no contingente de profissionais que paulatinamente integram os quadros de docentes (TEODORO, 1994), no discurso deste inquirido a fórmula para a revitalização da imagem social está precisamente na implementação de critérios de entrada na profissão mais seletivos e em que o domínio dos conhecimentos científicos assume como fator de seleção preponderante - uma avaliação operacionalizada através das classificações obtidas nas Universidades ("as pessoas saídas das Faculdades com as notas mais altas, essas é que deviam ser professores"). É através da composição entre os mundos inspirado e industrial, selecionado os candidatos que dão provas (BOLTANSKI ; THÉVENOT, 2006 [1991]), através das classificações obtidas, de estarem "munidos de bons conteúdos científicos" (legitimando também, por sua vez, uma melhoria do estatuto socioeconómico da profissão), que é possível "edificar a profissão" - e com reflexos na relação, quer com os discentes, quer com os pais ("Isso iria incutir nos alunos um maior respeito, nos pais e na sociedade"). A mesma perspetiva em torno da massificação enquanto problema a montante é secundada por outro professor, de Educação Física:

\begin{abstract}
"Temos o problema de antigamente: ia para professor quem não arranjava emprego em lado nenhum. "Não arranjo emprego; vou para professor". E agora estamos a pagar essa fatura, é evidente. Eu por acaso sempre quis ser professores desde o início, e há muitos assim. Agora há outros que não foi assim, e sabemos isso." (E7; escola A; professor de Educação Física; 20 anos de experiência profissional)
\end{abstract}

A massificação da profissão que ocorre ao longo das últimas décadas (TEODORO, 1994) enquanto resposta às necessidades de um sistema educativo em forte expansão do ponto de vista dos contingentes de alunos que acolhe - e o rigor no recrutamento de novos efetivos - traz no seu entender repercussões nocivas do ponto de vista do reconhecimento e prestígio social da profissão. Num sentido confluente parece ir a reflexão de outra professora quando compara o estatuto social, o respeito e reconhecimento (Honneth, 2001), dos profissionais do Ensino Básico e Secundário com os professores do Ensino Superior:

\footnotetext{
"Os professores do Ensino Superior são muito mais reconhecidos, são respeitados, considera-se que eles têm determinado estatuto. Tanto que não existe da mesma forma em relação aos professores do Ensino Secundário e Básico. [...] Portanto, a minha perceção leva-me a concluir que, contrariamente àquilo que acontecia quando eu era aluna, sobretudo no Ensino Secundário, havia mais consideração pelo professor. [...] Tudo isto tem uma explicação. Tem que ver com a carreira única com a qual eu discordo inteiramente. Foi criada uma carreira única entre o Ensino Básico e o Ensino Secundário e eu acho que não devia existir. Nós, professores do Ensino Secundário, estamos mais próximos do Ensino Superior. Devia haver, portanto, uma ligação mais estreita." (E31; escola D; professora de História; 39 anos de experiência profissional)
} 
A "consideração pelo professor" que, na sua memória enquanto aluna do Liceu ${ }^{8}$, existe e que se perde com a reestruturação do sistema de ensino na transição do país para o regime democrático em 1974, é explicada por um modelo de carreira única entre os vários ciclos que constituem o ensino obrigatório (TEODORO, 1994). A recuperação do estatuto profissional passa por isso, no entender da entrevistada, por uma reorganização da carreira docente no sentido de uma aproximação dos professores do Ensino Secundário aos professores do Ensino Superior. Sendo o Ensino Superior um patamar do sistema de ensino centrado no trabalho de transmissão (e desenvolvimento) de conhecimento científico (e onde, dessa forma, o mundo inspirado assume particular predominância nas lógicas de relacionamento dos docentes com os alunos), esta aproximação reside num entendimento de trabalho no Ensino Secundário como devendo estar primordialmente centrado na transmissão de conteúdos científicos das diferentes áreas disciplinares, distanciando-se desse modo da preponderância que a componente educativa e lógicas de proximidade na relação pedagógica com os alunos assumem nas formas atuantes dos professores ao nível do Ensino Básico - e tidos como suscetíveis de conter implicações nocivas para o estatuto profissional dos docentes (RESENDE, 2010; GOUVEIA, 2017). Esta perspetiva do Ensino Secundário como ensino préUniversitário constitui, neste sentido, a via para a revalorização (engrandecimento) do estatuto profissional dos docentes neste patamar concreto de ensino.

\section{A AÇÃO PLURAL NA RELAÇÃO COM OS PAIS E A DEMANDA DE RECONHECIMENTO}

A realidade docente nas últimas décadas no sistema educativo é marcada por profundas mudanças do ponto de vista das condições de exercício da atividade docente e que se traduzem em novas injunções no respetivo mandato. Estes assentam nos propósitos de maior colaboração, integração em equipas de trabalho e abertura na cooperação com outros atores (TARDIF ; LESSARD, 2009 [1999]). No quadro desta reconversão de práticas profissionais está, justamente, as injunções no sentido de uma mais estreita colaboração e envolvimento dos pais/Encarregados de Educação enquanto membros da comunidade educativa. A diminuição da dependência vertical das escolas em relação à administração central é acompanhada de uma mais forte integração horizontal - incluindo uma maior participação dos pais e Encarregados de Educação nas atividades educativas, no sentido de uma coresponsabilização, juntamente com outros elementos (como é o caso da presença de entidades externas no Conselho Geral) (SÁ, 2004; MAROY, 2008). Contudo, num olhar à escola micro, para lá das políticas educativas, e centrado nas interações, o relacionamento entre

\footnotetext{
${ }^{8}$ Até 1975 , os Liceus equivalem aos estabelecimentos de ensino secundário, oferecendo uma formação em Ciências e Humanidades e constitui a antecâmera de ingresso dos alunos no Ensino Superior - constituindo uma via de ensino paralela ao Ensino Técnico, orientado para a ingressão direta no mercado de trabalho. A esta oferta educativa diferenciada corresponde também populações escolares distintas do ponto de vista do seu perfil social (CRUZEIRO; ANTUNES, 1978). O Decreto-Lei no 260-B/75 marca a extinção de ambas as vias e o início do processo de criação do Ensino Secundário unificado em Portugal.
} 
professores e pais não deixa de ser feito de tensões e assente num diálogo que tem de ser permanentemente mantido e reconstruído, e não assente num acordo preestabelecido (MONTANDON, 1987) ou no desempenho de papéis (SILVA, 2006; RESENDE, 2010).

Ora, estas novas injunções em prol de uma maior colaboração não deixam de poder conflituar com diferentes perspetivas de professores em que a gramática inspirada assume relevância nas formas compósitas de agir com os pais/Encarregados de Educação (RESENDE, 2010; GOUVEIA, 2017) - no sentido em que podem ser privilegiados entendimentos estatutários e, nesse sentido, críticos àquilo que pode ser interpretado como ingerências na área de jurisdição do docente (ABBOTT, 1988).

Importa, todavia, salientar que as perspetivas manifestadas por membros deste grupo ocupacional não deixam de assumir formas plurais, por um lado, quando comparamos os discursos e lógicas atuantes dos professores entre si, como, por outro, no sentido em que estas formas de agir assentam em composições entre diferentes regimes de envolvimento (THÉVENOT, 2006) e que oscilam em função da cada situação. Não deixam por isso de ser identificáveis discursos assentes em composições entre a gramática cívica (no sentido de reconhecimento dos pais e Encarregados de Educação enquanto membros de uma mesma comunidade educativa) e o regime de envolvimento de proximidade (no sentido de uma acomodação nas formas de agir que passa pela assunção de lógicas negociais no relacionamento com aquele grupo de atores) - composições essas em que lógicas atuantes associadas ao mundo inspirado (reivindicadoras de autonomia decisória a nível pedagógico ou disciplinar) surgem, neste sentido, mais matizadas (RESENDE, 2010; GOUVEIA, 2017).

Porém, mesmo entre os docentes que assumem discursos e lógicas atuantes em que o mundo inspirado surge mais matizado, estas formas atuantes não deixa de assentar em rotinas incertas (BARRÈRE, 2002), de acomodação das práticas profissionais aos contextos de ensino com que se deparam, mais do que necessariamente em conceções sedimentadas. Por outro lado, mesmo assumindo lógicas negociais no relacionamento com os pais/Encarregados de Educação, os seus juízos críticos não deixam de se estender igualmente ao problema da degradação da autoridade e do estatuto social da profissão, mesmo que essas perspetivas críticas assumam feições mais esbatidas. Efetivamente, a questão da degradação do estatuto social da profissão não deixa de emergir nos seus discursos - quer do ponto de vista das expectativas produzidas pelas famílias relativamente às funções que devem compor o mandato e licença profissional (em que a função educativa parece assumir crescente importância), quer da perceção de uma deterioração do respeito nos modos de agir para com a figura do professor (e que é se estende ou transfere também para a relação com o discente). Nesse sentido, é uma demanda de reconhecimento (HONNETH, 2011) que parece ser transversal ao discurso dos professores, mesmo num quadro em que coexistem diferentes 
formas de agir na relação com os pais/EE (e alunos) tributárias de uma pluralidade compósita de discursos e lógicas atuantes no exercício da atividade profissional.

\section{REFERÊNCIAS}

ABBOTT, Andrew. The system of professions. An essay on the division of expert labor. Chicago: The Univ. of Chicago, 1988. 425 p.

ALMEIDA, Ana Nunes ; VIEIRA, Maria Manuel. A escola em Portugal. Lisboa: Imprensa das Ciências Sociais, 2000, 195 p.

BARRÈRE, Anne. Les enseignants au travail. Routines incertaines. Paris: L'Harmattan, 2002, $303 \mathrm{p}$.

BARROSO, João. (Org.) A escola pública: regulação, desregulação, privatização. Porto: Asa, 2003, 191 p.

BOLTANSKI, LUC ; THÉVENOT, Laurent. On justification. Economies of worth. Princeton: Princeton Univ., 2006 [1991], 350 p.

CRUZEIRO, Maria Eduardo; ANTUNES, M. L. Marinho. Ensino Secundário: duas populações, duas escolas. Análise Social, v.55, p. 443-502, 1978.

DEROUET, Jean-Louis. \& DEROUET-BESSON, Marie-Claude. Crise du projet de le démocratisation de l'ensiegnement ou crise d'un modèle de démocratisation? Les recompositions parallèles des formes de l'État et des formes de justice. In: DEROUET, J.-L. ; DEROUET-BESSON, M.C. (Dir.). Repenser la justice dans le domaine de l'éducation de la formation. Lyon: Peter Lang / INRP, 2009. p. 3-23.

DIOGO, Ana. Famílias e escolaridade: representações parentais da escolaridade, classe social e dinâmica familiar. Lisboa: Colibri, 1998, 223 p.

DUBET, François (Dir.). École, familles: le malentendu. Paris: Seuil, 167 p.

GAYET-VIAUD, Carole. La politesse dans la relation pédagogique. Éléments de réflexion sur le réglage de la distance entre maîtres et élèves. In: DESHOULIÈRES, V.; CONSTANTINESCU, M. (Dir.), Les funambules de l'affection. Maîtres et disciples. Clermont-Ferrand: Presses Universitaires Blaise Pascal, 2009. p. 113-133.

GOUVEIA, Luís. Porque se mobilizam os professores? Representações coletivas e coordenações e ações públicas dos professores do Ensino Básico e Secundário em função de juízos plurais sobre o que é um bom profissional de ensino num contexto de incerteza (Tese de Doutoramento). Lisboa: Faculdade de Ciências Sociais e Humanas, 2017.

HONNETH, Axel. Luta pelo Reconhecimento. Para uma gramática moral dos conflitos sociais. Lisboa: Edições 70, 2011. 308 p. 
HUGHES, Everett C. The sociological eye: selected papers. New Brunswick: Transaction Publishers, 1985. $584 \mathrm{p}$.

LANG, Vincent. La profession enseignant en France: permanence et éclatement. Éducation et francophonie, v.29, n.1, p. 52-69, 2001.

LANTHEAUME, Françoise. Mal-estar docente ou crise do ofício? Quando o belo trabalho desaparece e é preciso trabalhar de corpo e alma. Forum Sociológico, 15/16 (2a série), p. 141-56, 2006.

LANTHEAUME, Françoise; HÉLOU, Christophe. La souffrance des enseignants. Une sociologie pragmatique du travail enseignant. Paris: PUF, 2008, 173 p.

MAROY, Christian. Vers une régulation post-bureaucratique des systèmes d'enseignement en Europe? Sociologie et sociétés, 40 (1), p. 31-55, 2008.

MONTANDON, Cléopâtre. L'essor des relations famille-école. Problèmes et perspectives. In: PERRENOUD, P.; MONTADON, C. (Org.), Entre parents et enseignants: un dialogue impossible? Paris: Peter Lang, 1987. p. 23-47,

PERRENOUD, P. Le go-between: entre la familie et l'école, l'enfant messager et message. In: PERRENOUD, P.; MONTADON, C. (Org.), Entre parents et enseignants: un dialogue impossible? Paris: Peter Lang, p. 49-87, 1987.

RAYOU, Patrick e VAN ZANTEN, Agnès. Enquête sur les nouveaux enseignants. Changerontils l'école? Paris: Bayard, 2004. 301 p.

RESENDE, José Manuel. $O$ engrandecimento de uma profissão. Os professores do ensino secundário público no Estado Novo. Lisboa: FCT/Fundação Calouste Gulbenkian, 2003.

RESENDE, José Manuel. A sociedade contra a escola? A socialização política escola num contexto de incerteza. Lisboa: Instituto Piaget, 2010, 372 p.

RESENDE, José Manuel; CAETANO, Pedro. Da philia à hierarquia na escola: composições da ordem escolar?. In VIEIRA, M.M. et al (Org.). Habitar a escola e as suas margens geografias plurais em confronto. Portalegre: ESSE/IPP, p. 133-144, 2013.

SÁ, Virgínio. A Participação dos Pais na Escola Pública Portuguesa. Uma abordagem sociológica e organizacional. Braga: CIE-Instituto de Educação e Psicologia da Universidade do Minho, 2004, 557 p.

SILVA, Pedro. Analise sociológica da relação escola-família: um roteiro sobre o caso português, Sociologia: Revista do Departamento de Sociologia da FLUP, v.20, p. 443-464, 2010. 
SILVA, Pedro; STOER, Stephen R. Do pai colaborador ao pai parceiro. A reconfiguração de uma relação. In: STOER, Stephen R. ; SILVA, Pedro (Orgs.). Escola-Família. Uma relação em processo de reconfiguração. Porto: Porto, p. 13-25, 2005.

TARDIF, Maurice ; LESSARD, Claude. 0 trabalho docente: elementos para uma teoria da docência como profissão de interações humanas. Petrópolis: Editora Vozes, 2009 [1999], $317 \mathrm{p}$.

TEODORO, António. Política Educativa em Portugal. Educação, Desenvolvimento e Participação Política dos Professores. Lisboa: Texto, 1994, 347 p.

THÉVENOT, Laurent. L'action au pluriel. Sociologie des régimes d'engagement. Paris: La Découvert, 2006, 311 p.

VAN ZANTEN, AGNÈS. L'école de la périphérie. Scolarité et ségrégation en banlieue. Paris: PUF, 2001, $425 \mathrm{p}$.

VAN ZANTEN, AGNÈS. Choisir son école. Stratégies familiales et médiations locales. Paris: PUF, 2009, $304 \mathrm{p}$.

VIEIRA, Maria Manuel. Famílias e escola: Processos de construção da democratização escolar. In: VIEIRA, Maria Manuel et al (Orgs.). Democratização escolar: intenções e apropriações. Lisboa: Centro de Investigação em Educação-FC/UL, p. 75-103, 2003.

Revisão gramatical do texto sob a responsabilidade de: Sandra Cristina Nazário Brás Ferreira Rodrigues.E-mail: sfrodrigues1@sapo.pt 